\title{
Menelaah Pengambilan Keputusan Korban Pelecehan Seksual Dalam Melaporkan Kasus Pelecehan Seksual
}

\author{
Annisa Trihastuti', Fathul Lubabin Nuqul ${ }^{2}$ \\ ${ }^{1}$ Fakultas Psikologi \\ Universitas Islam Negeri Maulana Malik Ibrahim Malang \\ ${ }^{1}$ annstrhstuti@gmail.com, Lubabin \\ 2nuqul@uin-malang.ac.id
}

\begin{abstract}
Sexual harassment can occur everywhere, whether at work, in public places, or in the educational environment. This research aims to describe (1) the forms of sexual abuse experienced, (2) psychological effects, (3) the decision-making process of victims of sexual harassment, and (4) the expectations of victims of sexual abuse. This research used is qualitative research with phenomenology and in-depth interviews. The subjects in the study are the victims of sexual harassment as many as three women who are aged 21-25 years and who are active students in Malang. The subjects are divided into two categories. The results of the study are the The forms of sexual harrasment, the psychological effects on cognitive, affective, and behavior, the description about the process of decision making for the victims, and the victims hope that researcher describe on the discussion.
\end{abstract}

Keyword :

\begin{abstract}
Abstrak
Pelecehan seksual dapat terjadi di tempat kerja, di tempat umum, maupun di lingkungan pendidikan. Penelitian ini bertujuan untuk menelaah (1) bentuk pelecehan seksual yang dialami, (2) dampak psikologis, (3) proses pengambilan keputusan korban pelecehan seksual,dan (4) harapan korban pelecehan seksual. Penelitian yang digunakan adalah kualitatif dengan pendekatan fenomenologi dan teknik wawancara mendalam. Adapun subjek dalam penelitian merupakan korban pelecehan seksual sebanyak tiga orang perempuan berusia 21-25 tahun dan merupakan mahasiswa aktif di Malang. Hasil penelitian menunjukkan terdapat pelecehan seksual verbal dan non-verbal yang terjadi, dampak psikologis terkait dampak kognitif, afektif, psikomotorik dan perilaku, proses pengambilan keputusan korban yang melaporkan dan tidak melaporkan kasus, serta harapan korban yang dijabarkan dalam hasil dan pembahasan.
\end{abstract}

Kata kunci: Pengambilan Keputusan, Pelecehan Seksual, Harapan, Korban Pelecehan 


\section{Pendahuluan}

Kasus kekerasan terhadap perempuan kerap terjadi di Indonesia dari tahun ke tahun. Catatan Tahunan (CATAHU) Komisi Nasional Anti Kekerasan Terhadap Perempuan tahun 2019 menyebutkan terdapat 406.178 kasus kekerasan terhadap perempuan (KtP). Data tersebut meningkat dari jumlah pada tahun sebelumnya yakni sebanyak 57.732 kasus. Jumlah kasus tertinggi pada CATAHU 2019 adalah dalam kekerasan ranah personal 71\% (9.637), dilanjutkan ranah publik dan komunitas $28 \%$ (3.915), dan ranah negara $0,1 \%$ (16).

Kasus kekerasan dalam ranah personal yang tertinggi adalah kekerasan fisik sebanyak $41 \%$ (3.937 kasus) disusul dengan kekerasan seksual (31\%). Kasus pada ranah personal konsisten selama 5 tahun terakhir menjadi kasus tertinggi, termasuk kekerasan pada istri, pacar, mantan pacar, anak dan lainnya. Kasus kekerasan ranah publik dan komunitas memiliki angka tertinggi pada kekerasan seksual dibandingkan kekerasan lainnya, yakni sebanyak 64\% disusul dengan kekerasan fisik dan psikis sebanyak . Kekerasan seksual yang dimaksudkan adalah pencabulan (1.136), perkosaan (762), pelecehan seksual (294), dan persetubuhan (156). Terdapat 16 jumlah kasus ranah negara terkait kasus kriminalisasi dalam konflik sumberdaya dan kekerasan yang berdampak pada perempuan. Menurut CATAHU Komnas Anti Kekerasan terhadap Perempuan tahun 2019 tersebut, istilah persetubuhan dan pencabulan digunakan karena dasar hukum yang tertera pada KUHP. Sedangkan, pelecehan dalam hal ini juga dapat melingkupi pencabulan dan persetubuhan yang tidak ada rujukan hukumnya. Komnas perempuan mengartikan bahwa pelecehan seksual adalah Tindakan seksual dengan sentuhan fisik atau nnfisik dengan sasaran organ seksual atau seksualitas hingga korban merasa tidak naman tersinggung, dan terancam.

Kompas.com (2019) memaparkan hasil survey yang dilakukan pada November 2018 oleh Koalisi Ruang Publik Aman, bahwa dari 62.224 responden, 46,8 \% mengalami pelecehan. Pelecehan tersebut diklasifikasikan menjadi 19 bentuk pelecehan seksual delapan diantranya yakni siulan (5.392), komentar atas tubuh (3.628), main mata (3.325), disentuh (3.200), komentar seksis (2.515), didekati dengan agresif (1.445), komentar rasis (1.753), dan diraba (1.826). Hasil 
survey tersebut juga menyebutkan bahwa perempuan 13 kali lebih rentan mengalami pelecehan seksual di ruang publik dibandingkan laki-laki.

Kasus yang terlaporkan pada Komnas Perempuan, dan data yang ditemukan pada surey 2016 dan 2018 tersebut menunjukkan adanya kemungkinan ketimpangan antara angka pelecehan seksual yang dilaporkan dan jumlah kasus sebenarnya. Hal tersebut dapat disebabkan karena korban tidak mau melaporkan kasus pelecehan seksual yang dialaminya.

Padahal, berdasarkan penelitian yang dilakukan oleh Izzaturrohmah, \& Khaerani, (2018) terdapat dampak negatif yang dialami oleh korban pelecehan seksual, yakni depresi, sedih, merasa dirinya kotor, ketakutan, kepercayaan diri yang rendah, kesulitan mengontrol emosi, takut menikah, tertekan, terpuruk, dan jijik dengan dirinya sendiri. Tentunya hal ini akan menganggu kesejahteraan dan kemanan korban pelecehan seksual. Artaria (2012) menyebutkan bahwa terdapat efek lain dari pelecehan seksual yakni menimbulkan sedih, dendam, rasa marah, rasa malu, dan merasa tidak berarti. Hal tersebut juga bisa berdampak pada fisik korban yakni rambut rontok, penurunan kondisi tubuh karena sejalan dengan turunnya nafsu makan.

Efek yang ditimbulkan oleh kasus pelecehan seksual pada korban mempengaruhi korban dalam mengambil keputusan. Efek tersebut membuat korban tidak dapat langsung menentukan apakah melaporkan kasus atau tidak. Korban akan mengalami beberapa tahap reaksi psikologis, diantaranya: simptom somatik, penurunan kinerja, kecemasan, Menentukan apakah melaporkan kasus pelecehan seksual atau tidak (Orchowski, \& Gidycz, 2012). Korban memerlukan waktu dalam mempertimbangkan biaya (cost) dan mementukan beberapa pilihan yang mana akan menyebabkan penundaan dalam kasus pelecehan seksual (Balogh, et al, 2003).

Penelitian sebelumnya menyebutkan bahwa alasan seseorang tidak melaporkan kasus kriminal adalah adanya interaksi yang kompleks dan pengambilan keputusan korban untuk melaporkan kasus. Diantaranya adalah pengakuan bahwa kejahatan telah terjadi, pertimbangan atas apa yang harus dilakukan, respon dari keluarga kerabat dan kenalan, karakter dari korban dan sejumlah konteks sosial dan faktor komunitas (Wong \& Christman, 2008). 
Perlu adanya upaya dalam meningkatkan pelaporan kejahatan pada pihak berwajib atau lembaga lainnya. Identifikasi lebih lanjut terkait upaya tersebut, salah satunya tentang pengambilan keputusan korban (Wong \& Christman, 2008). Penelitian tentang pengambilan keputusan korban belum mendapatkan perhatian lebih termasuk tentang variabel dalam menentukan keputusan (Ahrens, Campbell, Ternier-Thames, Wasco, Sefl, 2007; Orchowski, \& Gidycz, 2012 ).

Peningkatan pelaporan akan memberikan dampak bagi masyarakat dan korban pelecehan seksual. Pada masyarakat akan meningkatkan kesadaran akan kasus ini, sedang untuk korban yakni meningkatkan kesempatan untuk mendapatkan perawatan medis dan pertolongan pertama secara psikologis untuk pulih dari kejadian yang berkenaan dengan psikis dan trauma (Sable, Danis, Mauzy, Gallager, 2006). Pelaporan yang meningkat juga akan meyadarkan pada sebuah institusi dalam menangani kasus tersebut.

Manfaat dari penelitian pengambilan keputusan ini juga merupakan wujud dari pencarian faktor secara spesifik agar korban mau melaporkan kasus yang terjadi. Penelitian sebelumnya menunjukkan bahwa, perlu adanya fokus penelitian tentang penyediaan dukungan spesifik untuk korban kekerasan agar mau mengungkapkan kasusnya. Penelitian tersebut juga menyebutkan bahwa penyediaan fasilitas/dukungan memungkinan untuk meningkatkan reaksi positif dan mengurangi reaksi negatif pada korban karena akan memberikan respon adaptif korban seperi kurangnya menyalahkan diri, approach coping, dan penyesuaian diri yang lebih baik (Kirkner, Lorenz, Ullman, 2017; Lorenz. Kirkner, \& Ullman, 2019).

\section{Metode Penelitian}

Metode kualitatif digunakan pada penelitian ini dengan pendekatan fenomenologis. Hal tersebut dikarenakan untuk pendekatan fenomenologi mendapatkan pengalaman subjektif seseorang dan mempelajari tentang kesadaran pokok seseorang atas sudut pandangnya (Moleong, 2007). Purposive sampling yang digunakan dengan kriteria mahasiswi aktif dan mendapatkan pelecehan seksual di sekitar kampus. Peneliti pada awalnya mendapat cerita dari salah satu teman yang dijadikan subjek bahwa ia mendapat pelecehan seksual di kampus dan 
tidak melaporkan kasusnya. Kemudian peneliti mencari subjek yang disekitar dan mau terbuka untuk menceritakan kasus pelecehan seksual yang dialami. Peneliti menggunakan 3 subjek mahasiswi yang berkuliah di salah satu universitas di Malang. Tidak ada kesengajaan dalam mengambil lokasi penelitian.

Adapun variasi subjek yang digunakan adalah yang telah melaporkan kasus dan yang belum melaporkan kasus. Penelitian berfokus pada bentuk pelecean seksual, kondisi psikologis pada korban setelah kejadian pelecehan seksual, proses pengambilan keputusan korban, dan harapan korban akan perlakuan yang diterima. kejadian pelecehan seksual juga dibatasi oleh perlakuan yang dilakukan disekitar kampus.

Pengolahan data dilakukan dengan menulis verbatim dan ditulis pada open coding. Kemudian dilakukan pencarian dan pemadatan fakta dengan metode axial coding. Selective coding merupakan tahap selajutnya yang berfungsi sebagai pemilahan aspek psikologis dari permasalahan penelitian yang dituju. Adapun selanjutnya, pembuatan temuan data lapangan dan pembahasan dibuat dengan paduan temuan ilmiah lainnya. Keabsahan data dilakukan dengan keajegan peneliti, triangulasi dengan menanyakan wakil kepala penjaga keamanan, teman subjek, dan dokumentasi, serta uraian rinci penelitian.

\section{Hasil dan Pembahasan}

\section{Jenis Pelecehan yang Terjadi}

Pada Subjek 1, terdapat dua kali pelecehan seksual yang dialaminya sebagai bentuk pelecehan. Pelecehan pertama berupa perilaku memegang paha dan pelecehan kedua merupakan sentuhan di belakang punggung dan mengenai pakaian dalamnya. S1 juga tersinggung dengan beberapa perkataan dari pelaku yang mengenai apakah S1 ingin menjadi pacar atau tidak dan tersinggung saat beberapa kali bapak S mengumumkan bahwa S1 pacarnya. Walaupun hal itu sudah dijelaskan namun pelaku tetap memanggil S1 bahwa S1 merupakan pacarnya.

\footnotetext{
"Kan kalo masuk X tidak usah pakai stnk, tapi dia ini stop me. terus bilang 'Hei ini pacarku' he told the others ini pacarku, terus I said, pak jangan gitu. terus he touch me ágain, not shoulder, but belakang. Kan dia dulu touch disini (memegang bahu) then he touch here (menggeser tangan ke belakang punggung) maybe he touched it, my bra." (TW.S1.12/10/19-W.S1.8).
} 
S2 mendapatkan pelecehan seksual berupa sentuhan di lengan atas menuju bahunya. S2 mendapatkan hal tersebut saat akan keluar gerbang kampusnya. Hal tersebut terjadi dengan kronologi S2 akan keluar pintu gerbang dalam keadaan sepi dan sendirian kemudian, Pelaku memberhentikan S2 dengan memegang stang motor S2. Pelaku kemudian menatap wajah S2.

“..Iya nafsu gitu, tuh tu iya kayak gitu (menunjuk wajah peneliti yang menatap dengan membuka mata dengan lebar). Njir ni anak kurang jatah apa gimana ya. Terus dia pegang STNK ku sa. Kamu orang bali? Iya pak. Besok bawain pie susu ya sama kacang itu lo kacang oh iya pak iya, aku iya iya aja kan. aku mulai gak nyaman kan. Yah, (sambil memegang tangan kanan ke lengan atas tangan kiri disusuri dari lengan atas ke sikut)." (TW.S2.15/10/19-W.S2.5).

Pada S3 pelaku memberikan pertanyaan bersifat seksual di awal chat. Pelaku menduga bahwa S3 pernah melakukan hubungan seksual. S3 kemudian tidak memahami maksud dari perkataan 'nyicip' dari pelaku dan pelaku menjelaskan dengan kata tersebut. Setelah menjelaskan kata tersebut, pelaku menjelaskan tentang kondisi hubungan seksual dengan pasangannya.

“...Orangnya udah nikah, 'enak wes tembak dalam gitu'. Aku kan gak paham ya, tapi gak tak reken ambek aku, opo sih, bahas liyane. 'Wes mas, di dungakno ae' ngono. 'dungakno ndang dihalalkan', aku bilang. terus, eh, orangnya tiba-tiba bilang gini, 'halah kamu paling wes nyicip dek'. 'Hah nyicip apaan?' Aku ngono. 'Masa gak paham?' 'Ora'. Aku wes sensi kan, apaan sih orang iki, ini ngomonya frontal disini gapapa? Terus orang itu tiba-tiba gini 'masa gak tau dek' 'gak'. 'Maksudnya nyicip itu ada cowok, minum itunya cewek, terus yang cewek isep itunya cowok'..." (TW.S3.5/11/19-W.S3.4).

Perilaku yang dialami subjek pertama atau S1 merupakan perilaku pelecehan seksual, hal tersebut dikarenakan S1 mengatakan ketidaksukaannya saat dilakukan pelecehan seksual. Sebagaimana menurut Rowman (2011), pelecehan seksual merupakan perilaku dan komentar berbasis gender yang tidak diinginkan kepada seseorang yang menganggap bahwa hal tersebut merupakan serangan atau ancaman.

Pada subjek kedua (S2), subjek mendapatkan perilaku berupa sentuhan di lengan atas menuju sikutnya di tangan kiri. Disaat yang bersamaan S2 mendapatkan tatapan yang tidak disukai. Hal tersebut termasuk kedalam pelecehan seksual unwanted sexual attention. (Buchanan \& Harrel, 2011), 
Adapun subjek 3 (S3) menunjukkan adanya pelecehan seksual yang terdapat pada pesan pribadi di twitter. Hal tersebut dikategorikan pada pelecehan seksual verbal sebagaimana yang dikategorikan oleh Fisher, Cullen. \& Turner. (2000) yang membagi viktimisasi sebagai verbal dan visual. Viktimisasi verbal pada S3 adalah pesan tidak sesononoh dan bertanya tentang hubungan seksual yang dialami (Fisher, Cullen. \& Turner, 2000). Sebagaimana tabel 1 Klasifikasi bentuk pelecehan seksual. 


\section{Dampak Psikologis}

Dampak kognitif pada ketiga subjek yakni mengingat kata-kata tersebut dan menjadi distress pada kehidupan keseharian. Terdapat dalam mengingat kata, ada yang membuat hal tersebut faktor untuk tidak betah tinggal di Indonesia, dan subjek kedua menggeneralisasikan dengan stimulus tidak mengenakkan lainnya.

Tabel 1

Klasifikasi bentuk pelecehan seksual

\begin{tabular}{cll}
\hline Subjek & \multicolumn{1}{c}{$\begin{array}{c}\text { Jenis Pelecehan } \\
\text { Seksual }\end{array}$} & \multicolumn{1}{c}{ Bentuk Pelecehan seksual } \\
\hline S1 & $\begin{array}{l}\text { Pelecehan seksual non- } \\
\text { verbal }\end{array}$ & $\begin{array}{l}\text { Sentuhan pada paha dan belakang } \\
\text { punggung. }\end{array}$ \\
\hline S2 & $\begin{array}{l}\text { Pelecehan seksual non- } \\
\text { verbal }\end{array}$ & $\begin{array}{l}\text { Tangan pelaku menyusuri lengan } \\
\text { bagian atas. }\end{array}$ \\
\hline S3 & $\begin{array}{l}\text { Pelecehan seksual } \\
\text { verbal }\end{array}$ & $\begin{array}{l}\text { Pelaku menyampaikan pesan berbau } \\
\text { seksual dan berkaitan hubungan } \\
\text { seksual korban. }\end{array}$ \\
\hline
\end{tabular}

Dampak perilaku atau psikomotorik pada korban pelecehan seksual berupa gejala pada fisik maupun perubahan pada perilaku. Gejala pada fisik yakni jantung berdebar, sesak nafas, sakit dan pusing. Perubahan perilaku yang dilakukan oleh korban pelecehan seksual yakni menghindari pelaku, memasang wajah serius ketika bertemu pelaku, mengurangi intensitas bermain twitter, dan merubah cara berpakaian dengan mengenakan jeans.

Sebagaimana penelitian yang dilakukan oleh Artaria (2012) korban setelah mendapatkan kejadian pelecehan seksual teringat akan kasus yang dialami. Seperti yang dialami oleh S3, S3 akan teringat kasus pelecehan seksual yang dialami dan menangis atas teraganggunya pikiran tersebut sebagaimana yang disebutkan oleh Fuadi (2011) bahwa korban akan mengalami flashback atau mengingat kembali atas kejadian yang dialami.

Kemudian dampak afeksi pada korban pelecehan seksual adalah pada perasaan tidak nyaman, marah, kesal, menyalahkan diri sendiri, merasa ada yang diambil, dan rendah diri. Fuadi (2011) menegaskan bahwa korban akan cenderung menyalahkan dirinya atas kejadian pelecehan seksual yang terjadi. Sejalan dengan hal tersebut Quick dan Mayfayden (2017) menegaskan bahwa korban akan 
mengevaluasi diri terkait kasus pelecehan seksual sebagai orang yang bersalah pada kasus. Hal tersebut dialami pada S2 dan S3 yang berpikiran menyalahkan diri atas kasus yang terjadi. Berikut tabel 2 tentang dampak psikologis korban.

\section{Pengambilan Keputusan}

S1 dan S2 tidak melaporkan kasus pelecehan seksual. Dapat disimpulkan bahwa adanya alasan faktor yang mempengaruhi adalah (1) Keraguan apakah hal tersebut pelecehan atau bukan, (2) Mendapatkan saran dari orang terdekat untuk tidak melaporkan, (3) tidak menginginkan ada konflik, (4) tidak mengetahui alur melaporkan kasus, (5) tidak ingin terjadi masalah dan hambatan pada proses perkuliahan, (6) meniru perilaku orang sekitar, (7) beranggapan melaporkan kasus adala tindakan yang sia-sia.

Tabel 2

Klasifikasi dampak psikologi korban

\begin{tabular}{clll}
\hline Subjek & Dampak Kognitif & \multicolumn{1}{c}{ Dampak Afeksi } & \multicolumn{1}{c}{$\begin{array}{c}\text { Dampak psikomotorik dan } \\
\text { perilaku }\end{array}$} \\
\hline S1 & Distress & Marah, membenci & $\begin{array}{l}\text { Deg-degan, } \\
\text { Selalu menghindari pelaku }\end{array}$ \\
\hline S2 & Distress & $\begin{array}{l}\text { Marah., kesal, } \\
\text { menyalahkan diri } \\
\text { sendiri }\end{array}$ & Deg-degan, sesak nafas, \\
\hline S3 & Mengingat kejadian & $\begin{array}{l}\text { Takut, jijik, marah, } \\
\text { kecewa, } \\
\text { menyalahkan diri } \\
\text { secara berulang, }\end{array}$ & $\begin{array}{l}\text { Menangis, } \\
\text { mengurangi intensitas bermain } \\
\text { sosial media, } \\
\text { merubah cara berpakaian }\end{array}$ \\
\hline
\end{tabular}

Menurut Ruback dkk (1984) pengaruh sosial (social influence) dapat mempengaruhi korban dalam menentukan apa yang harus dilakukan. Maka dalam kasus pelecehan S1, suami mempengaruhi pilihan korban untuk tidak melaporkan kasus. Disebutkan oleh kedua subjek, S1 dan S2 tidak menginginkan adanya konflik berkelanjutan dengan pelaku. Alasan menghindari konflik atau konsekuensi atas tindakan melaporkan kasus merupakan salah satu pertimbangan pada korban untuk tidak melaporkan kasus (Artaria, 2012). Selain hal tersebut, Tidak mengetahui alur pelaporan kasus juga berpengaruh pada pertimbangan untuk melaporkan kasus (Fisher, Cullen \& Turner., 2000). 
Berikut proses pengambilan keputusan tidak melaporkan kasus pelecehan seksual (1) terjadi pelecehan seksual berupa sentuhan di paha, punggung, dan lengan atas. Kemudian, subjek menganggap dirinya sebagai korban dengan pertimbangan. (2) pada tahap kedua, subjek merasakan dampak psikologis berupa tertekan, menyalahkan diri sendiri, marah, kesal, sedih, kecewa, dan takut akan kejadian selanjutnya (vunarbeility) dalam hal ini subjek mendapatkan interfensi sosial yakni dengan menceritakan kepada teman untuk mengurangi distress, kemudian mendapatkan saran tidak melaporkan, dan melihat role model yang tidak membantu melaporkan kasus. (3) Tahap ketiga yakni Pertimbangan analisis costbenefit dan sikap terhadap pilihan antara lain yang didasarkan pada stored knowledge (tidak mengetahui alur melaporkan) dan beranggapan bahwa melapor adalah tindakan sia-sia. Kemudian terdapat konflik dalam diri yakni tidak ingin menimbulkan masalah dan menghambat dalam perkuliahan. Sehingga dari 3 tahapan proses tersebut, yakni dampak psikologis, social influence, dan cost-benefit analyze, korban tidak melaporkan namun menyelesaikan konflik. Korban selalu menghindari pelaku dan merasa was-was jika bertemu pelaku.

Berbeda dengan korban yang melaporkan. Berdasarkan pengambilan keputusan korban Subjek 3 yang melaporkan kasus, hal tersebut dilakukan karena (1) merasakan tekanan psikologis yang mendalam, (2) tidak ingin terdapat korban lainnya, (3) mendapatkan bantuan untuk melaporkan, (4) mengalami kasus pelecehan seksual sebelumnya yang tidak mampu dilaporkan.

Berikut proses pengambilan keputusan korban melaporkan kasus pelecehan seksual (1) terjadi pelecehan seksual berupa pesan pribadi di twitter. (2) pada tahap kedua, subjek merasakan dampak psikologis Menyalahkan diri sendiri, sedih, menangis selama seminggu, sakit, mengingat kejadian berulang. dalam hal ini subjek mendapatkan intervensi sosial yakni dengan menceritakan kepada teman dan mendapatkan bantuan untuk melaporkan kasus sebagai saksi. (3) Dalam pertimbangan analisis cost-benefit korban memiliki kesempatan dalam melaporkan, mempunyai keinginan agar tidak terdapat korban lain, terdapat bukti, dan terdapat korban yang juga ingin melaporkan. Selain itu terdapat faktor lain yang berpengaruh yakni, stored knowledge berupa pengalaman korban dalam mendapatkan pelecehan seksual dan disentuh dadanya. Sehingga dari 3 faktor dan 
proses tersebut, yakni dampak psikologis, social influence, dan cost-benefit analyze, serta pengaruh lain dari stored knowledge korban mau melaporkan kasus.

Subjek 3 merasa rentan dan mendapatkan tekanan secara psikologis atas perilaku pelecehan seksual yang didapatkan. Hal tersebut diperkuat karena adanya presepsi ketidakadilan dan kerentanan akan pelecehan seksual yang dialami (Ruback, dkk, 1984). Selalu teringat perkataan dari pesan pelaku pada beberapa hari, menyalahkan diri dan perasaan tidak terima atas perlakuan disimpulkan sebagai dampak negatif menjadi korban pelecehan seksual (Izzaturrohmah, \& Khaerani, 2018).

Pengaruh dari pelecehan seksual sebelumnya mempengaruhi subjek S3 untuk melaporkan kasus. Perasaan tertekan dan mengingat kembali kejadian pelecehan seksual yang tidak dapat dilaporkan (karena tidak mempunyai alat bukti) saat mengalami pelecehan seksual yang pertama mendorong S3 melaporkan pada kasus pelecehan yang kedua. pengalaman pada pelecehan seksual, rasa sakit yang dirasakan, dan peluang untuk tidak melaporkan menjadi pengalaman dan pengetahuan bagi korban dalam memutuskan melaporkan perkara atau tidak. sebagaimana pada proses pengambilan keputusan tahap ketiga, stored knowledge atau pengetahuan sebelumnya berpengaruh pada penentuan sikap melaporkan kasus (Ruback, dkk, 1984).

Terdapat perbedaan antara korban yang melaporkan (S3) dan korban yang tidak melaporkan (S1 dan S2). Korban yang tidak melaporkan mendapatkan perlakuan pelecehan seksual secara langsung dan dilakukan oleh civitas akademik. Korban dalam hal ini, masih bertatap muka dan bertemu dengan pelaku. Berbeda dengan korban yang melaporkan tidak bertemu dan berinterkasi secara langsung di dunia nyata. Korban yang tidak melaporkan, korban harus tetap bertatap muka dengan pelaku.

Pada korban yang tidak melaporkan terdapat beberapa alasan pertimbangan untuk tidak melaporkan diantaranya subjek takut bermasalah pada kuliah/kehidupan kampusnya, dan menjaga nama baik. selain hal tersebut, pada aspek stored knowledge korban S1 dan S2 tidak terdapat kasus pelecehan seksual yang dialami secara langsung. Pada subjek yang melaporkan terdapat stored knowledge, yang berisikan pengalaman subjek berupa menjadi korban pelecehan 
seksual. Hal tersebut memperkuat S3 untuk melaporkan kasus karena menjadi dua kali korban pelecehan seksual.

\section{Harapan Korban pada Kasusnya}

Ketidakmampuan korban dalam melaporkan, terkait dengan pertimbangan risiko yang dimiliki, membuat korban mencari solusi lain. Pertimbangan resiko terkait institusi dan lembaga menjadi faktor utama tidak melaporkan, berkaitan dengan status korban yang tidak melaporkan sebagai mahasiswa. Korban yang merasa tidak memiliki kekuatan dalam upaya melaporkan, mengambil solusi dengan menghindari pelaku (melewati jalan lain agar tidak bertemu pelaku) dan sekedar menyampaikan pada teman. Hal tersebut menandakan perlunya usaha lebih pada korban, yang menjadikan sebuah tekanan bagi korban yang masih berkuliah, untuk mencegah kerentanan perlakuan pelecehan yang tetap berdampak pada psikologis korban. Padahal korban tetap berharap adanya kesadaran pelaku atas perlakuan yang dilakukan sebagai bentuk kesalahan. Korban berharap menyampaikan hal tersebut dengan aman dan tanpa tekanan dari pihak manapun, baik terkait respon negatif yang diberikan maupun ketidakpercayaan atas penyelesaian kasus.

\footnotetext{
"My hope is, saya kan tidak mau ribut kena masalah, cuman my hope I want bapak itu sadar, its wrong, dan tidak mau dia mungkin bilang, victim, tapi gamau yang yang lain juga seperti saya. Yang penting Saya gak kepengen bapak itu keluar dari kampus X. I mean bapak itu harus sadar kalau dan Saya kan tidak suka, yang saya tidak suka sama sekali itu kan yang pegang-pegang itu saya bisa avoid. Yang tidak bisa avoid itu masalah pacaran. Ini pacar saya dan saya itu sudah menikah, masalahnya itu, I want him to understand." (TW.S1.12/10/19-W.S1.39).
}

Terdapat harapan korban untuk mendapatkan rasa tenang dan aman saat melaporkan kasus. Yakni saat S2 meminta bantuan dalam bentuk tersirat kepada salah satu dosen. S2 tidak berani menyampaikan secara eksplisit yang dimaksud. Dalam hal ini, S2 berharap terdapat bantuan profesional yang bisa dimanfaatkan untuk membantu korban mengungkap permasalahan. Alasan ini pula yang menjadikan korban S2 tidak berani melaporkan kasus, karena bantuan profesional yang diharapkan tidak mau mengungkap kasus dari sudut kasus yang berbeda (bukan pelecehan seksual). 
Harapan atas perilaku yang dimunculkan, terkait dengan peran sosial yang dimiliki oleh pelaku berkaitan dengan nilai dan kondisi lingkungannya. Seperti harapan yang dipaparkan S2 bahwa dengan kondisi lingkungan religius, S2 berharap pelaku turut menjaga sebagaimana civitas akademik lain menjaga perilaku dan norma umum yang berlaku pada lingkungan tersebut.

Peran sosial, juga terkait harapan sosial diungkapkan oleh S3. S3 memaparkan bahwa pelaku S3 merupakan kakak senior yang terkenal aktif beroganisasi serta berprestasi di kampusnya saat itu. Hal tersebut cukup mengecewakan dirinya dan menghancurkan harapan serta kepercayaan terhadap citra diri yang dibangun pelaku, atas pelecehan yang dilakukan karena seharusnya kakak senior melindungi dan mengayomi adek tingkatnya.

Berdasarkan pemaparan dari ketiga subjek, maka harapan yang diinginkan adalah (1) pelaku menyadari kesalahan perilaku, (2) korban mendapat bantuan dari pihak lain, (3) pelaku mendapatkan balasan, (4) pelaku menghormati citra religiusitas tempat institusi berada, (5) tidak ada korban lainnya, dan (6) dapat melaporkan dengan aman dan mendapat tanggapan efektif dari tempat pelaporan.

\section{Kesimpulan}

Dalam Penelitian ini, terdapat dua bentuk pelecehan seksual yang terjadi, yakni pelecehan seksual verbal dan non-verbal. Bentuk pelecehan verbal berupa pesan pribadi di Twitter yang berisi pesan bersifat seksual, tuduhan melakukan aktivitas seksual dengan pacar korban, dan kondisi hubungan seksual pribadi pelaku. Bentuk pelecehan non-verbal adalah menyentuh bagian tubuh korban yakni paha, punggung, dan bahu. Pelecehan seksual dilakukan oleh civitas akademik kampus.

Dampak Psikologis pada korban pelecehan adalah menyalahkan diri sendiri, marah, sedih kesal, merasa rendah diri, takut, tertekan, cemas, panik, waspada, jijik dan mengingat kejadian secara berulang. Dampak psikologis tersebut disertai usaha dalam bentuk perilaku yakni menghindari pelaku, menghindari hal yang mengingatkan pada kejadian, dan merubah perilaku agar tidak terkena resiko pelecehan. 
Terdapat dua pengambilan keputusan korban yang dilakukan yakni melaporkan kasus dan tidak melaporkan kasus. Pada korban yang tidak melaporkan kasus, beberapa pertimbangan dan faktor yang mempengaruhi adalah (1) Keraguan apakah hal tersebut pelecehan atau bukan, (2) Mendapatkan saran dari orang terdekat untuk tidak melaporkan, (3) tidak menginginnkan ada konflik, (4) tidak mengetahui alur melaporkan kasus, (5) tidak ingin terjadi masalah dan hambatan pada proses perkuliahan, (6) meniru perilaku orang sekitar, dan (7) beranggapan melaporkan kasus adala tindakan yang sia-sia. Pada korban yang melaporkan kasus beberapa pertimbangan dan faktor yang mempengaruhi adalah (1) merasakan tekanan psikologis yang mendalam, (2) tidak ingin terdapat korban lainnya (3) mendapatkan bantuan untuk melaporkan, (4) mengalami kasus pelecehan seksual sebelumnya yang tidak mampu dilaporkan.

Berdasarkan pemaparan korban terdapat harapan yang dimiliki korban terkait kasus pelecehan seksual yang dialami, yakni: (1) pelaku menyadari kesalahan perilaku, (2) korban mendapat bantuan dari pihak lain, (3) pelaku mendapatkan balasan, (4) pelaku menghormati citra religiusitas tempat institusi berada, (5) tidak ada korban lainnya, dan (6) Korban dapat melaporkan dengan aman dan mendapat tanggapan efektif dari lembaga yang dilaporkan.

\section{Daftar Pustaka}

Ahrens, C.E. Campbell R, Ternier-Thames, NK, Wasco, SM., Sefl, T (2007) Deciding Whom to Tell: Expectations and Outcomes of Rape Survivors' First Disclosures Psychology of Women Quarterly 31(1):38-49 DOI 10.1111/j.1471-6402.2007.00329.x

Artaria, M.D. (2012). Efek Pelecehan Seksual di Lingkunan Kampus: Studi Prelimenier. Jurnal Bio Kultur, vol.1, no.1. hal 53-72.

Balogh, DW. Kite ME, Pickel, KL., Canel,. D. Schroeder J. (2001). The Effects of Delayed Report and Motive for Reporting on Perceptions of Sexual Harassment. Journal Sex Roles. Vol. 48. DOI: 10.1023/A:1022990530657

Buchanan, N.T\& Harrell, Z.A. (2011). Surviving Sexual Harassment: Coping With, Recognizing, and Preventing Unwanted Sexual Behaviors in the Workplace (Surviving Sexual Violence book). Rowman \& Littlefiled Publisher: Maryland 
Cortina, L.M \& Berdajl, J.L. (2008). Sexual harrasment in organizarinons: a decade of research in review. Vol.Imicro approaches

Fisher, B.S., Cullen. F.T., \& Turner M.G. (2000). The Sexual Victimization of College Women. Bureau of Jutice. Statistics. US.

Fuadi, A. (2011). Dinamika psikologis kekerasan seksual: sebuah studi fenomenologi Psikoislamika: Jurnal Psikologi Islam, vol. 8, No.2, 191-209

Izzaturrohmah, \& Khaerani, N. M. (2018) Peningkatan Resiliensi Perempuan Korban Pelecehan Seksual Melalui Pelatihan Regulasi Emosi $\begin{array}{llll}\text { Psikohumaniora, Jurnal } & \text { Psikologi } & 3(1) & 117-140\end{array}$ DOI: http://dx.doi.org/10.21580/pjpp.v3i1.2527

Kirkner, A. Lorenz, K. Ullman, S.E.(2017). Recommendations for Responding to Survivors of Sexual Assault: A Qualitative Study of Survivors and Support Providers. Journal of Interpersonal Violence 1-24 DOI: $10.1177 / 0886260517739285$

Komisi Nasional Anti Kekerasan Terhadap Perempuan: (2020) Catatan Tahunan Kekerasan Terhadap Perempuan 2019. Komnasperempuan.go.id

Kompas (2019) Survei KRPA: 46,8 Persen Orang Pernah Dilecehkan di Transportasi Umum, Mayoritas di Bus. Diakses, 25 April 2020

Lorenz, K. Kirkner, A. \& Ullman, S.E. (2019). A Qualitative Study of Sexual Assault Survivors' Post-Assault Legal System Experiences . Journal Of Trauma \& Dissociation. Vol. 20, No. 3, 263-287 https://doi.org/10.1080/15299732.2019.1592643

Moleong, L.J. (2007). Metodologi Penelitian Kualitatif. PT Remaja Rosdakarya: Bandung

McDonald, P. (2012). Workplace sexual harassment 30 years on: A review of the literature. International Journal of Management Reviews, 14, 1-17. http://dx.doi.org/10.1111/j.1468-2370.2011.00300.x

Orchowski, LM \& Gidycz CA (2012) To whom do college women confide following sexual assault? A prospective study of predictors of sexual assault disclosure and social reactions. Violence against women, 18(3) 264-288

Quick, J.C., \& McFayden, M.A. (2017). Sexual Harrasment: Have We Made Any Progress. Joyrnal of Occupational Health Psychology. Vol. 22 NO. 3 286298. 1076-8998/17/\$12.00 http://dx.doi.org/10.1037/ocp0000054

Ruback, B.R., Greenberg, M.S., \& Westcott, D.R. (1984). Social Influence and Crime-VIctim Decision Making. Journal of Social Issues. Vol. 40. No. 1, 1984, pp. 51-16 
Sable, M. Danis, F. Mauzy, D. Gallagher, S. (2006) Barriers to reporting sexual assault for woman and men: Perspectives of college student

Wong, K \& Christmann, K. (2008). The role of victim decisionmaking in report of hate crime. Safer Communities 7 2, 24-35. 